\title{
Growth phase dependent hydrogen isotopic fractionation in alkenone-producing haptophytes
}

\author{
M. D. Wolhowe ${ }^{1}$, F. G. Prahl ${ }^{1}$, I. Probert ${ }^{2}$, and M. Maldonado ${ }^{3}$ \\ ${ }^{1}$ College of Oceanic and Atmospheric Sciences, Oregon State University, Corvallis OR USA \\ ${ }^{2}$ Station Biologique de Roscoff, Centre National de la Recherche Scientifique, Roscoff, France \\ ${ }^{3}$ Department of Earth and Ocean Sciences, University of British Columbia, Vancouver B.C., Canada
}

Received: 26 March 2009 - Published in Biogeosciences Discuss.: 16 April 2009

Revised: 29 July 2009 - Accepted: 4 August 2009 - Published: 19 August 2009

\begin{abstract}
Recent works have investigated use of the hydrogen isotopic composition of $\mathrm{C}_{37}$ alkenones $\left(\delta D_{\mathrm{K} 37 \mathrm{~s}}\right)$, lipid biomarkers of certain haptophyte microalgae, as an independent paleosalinity proxy. We discuss herein the factors impeding the success of such an application and identify the potential alternative use of $\delta D_{\mathrm{K} 37 \mathrm{~s}}$ measurements as a proxy for non-thermal, physiological stress impacts on the $U_{37}^{K^{\prime}} \mathrm{pa}$ leotemperature index. Batch-culture experiments with the haptophyte Emiliania huxleyi (CCMP 1742) were conducted to determine the magnitude and variability of the isotopic contrasts between individual $\mathrm{C}_{37}$ alkenones. Further experiments were conducted with Emiliania huxleyi (CCMP 1742) and Gephyrocapsa oceanica (PZ3-1) to determine whether, and to what extent, $\delta D_{\mathrm{K} 37 \mathrm{~s}}$ varies between the physiological extremes of nutrient-replete exponential growth and nutrientdepleted senescence. Emiliania huxleyi was observed to exhibit an isotopic contrast between di- and tri-unsaturated $\mathrm{C}_{37}$ alkenones $\left(\alpha_{\mathrm{K} 37: 3-\mathrm{K} 37: 2} \approx 0.97\right)$ that is nearly identical to that reported recently by others for environmental samples. Furthermore, this contrast appears to be constant with growth stage. The consistency of the offset across different growth stages suggests that a single, well-defined value for $\alpha_{\mathrm{K} 37: 3-\mathrm{K} 37: 2}$ may exist and that its use in an isotope massbalance will allow accurate determination of $\delta D$ values for individual alkenones without having to rely on time- and labor-intensive chemical separations. The isotopic fractionation between growth medium and $\mathrm{C}_{37}$ alkenones was observed to increase dramatically upon the onset of nutrientdepletion-induced senescence, suggesting that $\delta D_{\mathrm{K} 37 \mathrm{~s}}$ may
\end{abstract}

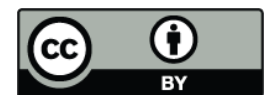

Correspondence to: M. D. Wolhowe (mwolhowe@coas.oregonstate.edu) serve as an objective tool for recognizing and potentially correcting, at least semi-quantitatively, for the effects of nutrient stress on $U_{37}^{K^{\prime}}$ temperature records.

\section{Introduction}

\subsection{The premise of alkenone $\delta D$ as a water composition proxy}

Englebrecht and Sachs (2005) measured $\mathrm{C}_{37}$ alkenone hydrogen isotopic composition $\left(\delta D_{\mathrm{K} 37 \mathrm{~s}}\right)$ in suspended particulate matter (SPM) and surface sediments around the Bermuda Rise, and observed relatively consistent hydrogen isotopic fractionation factors relative to the overlying surface water $\left(\alpha_{\mathrm{K} 37 \mathrm{~s}-\text { water }}\right)$. Given this finding and results from a batch culture experiment with the alkenone producer Emiliania huxleyi, they argued that alkenones may provide a reliable paleoproxy for the $\delta D$ composition of surface water.

Non-exchangeable hydrogen in photosynthesized organic matter (e.g. from lipids) necessarily reflects the isotopic composition of the water from which it was produced (e.g. Yakir and DeNiro, 1990). Interpretation of bulk lipid $\delta D$ measurements is complicated, however, by the differences in net isotopic fractionation exhibited by different organisms and by different individual compounds. These differences are due to a host of factors, including differences in water transport into and out of the cell, biosynthetic pathways and relative synthetic rates (Sessions et al., 1999). Alkenones, though, are a species-specific biomarker, unique to a small number of haptophyte algae and usually assumed, in marine sediments younger than $\sim 280 \mathrm{ky}$, to be produced predominantly by Emiliania huxleyi (Herbert, 2003). If the assumption is

Published by Copernicus Publications on behalf of the European Geosciences Union. 
made that a single measured hydrogen isotopic fractionation factor, $\alpha$, defined as:

$\alpha_{\mathrm{K} 37 \mathrm{~s}-\text { water }}=\frac{\delta D_{\mathrm{K} 37 \mathrm{~s}}+1000}{\delta D_{\mathrm{water}}+1000}$

is applicable to alkenone synthesis by E. huxleyi, then fossil alkenones (younger than $280 \mathrm{ky}$ ) could provide a useful proxy for the isotopic composition of surface water. Alkenones are an attractive basis for such a proxy because of their utility as a coeval paleothermometer (Brassell, 1993). Given certain constraints on the regional isotopic composition of precipitation and runoff, the $\delta D$ of surface water may serve, in turn, as a quantitative proxy for salinity (e.g. Benway and Mix, 2004).

However, the assumption of a single, well-defined value of $\alpha_{\mathrm{K} 37 \mathrm{~s}-\text { water }}$ is by no means trivial. Time- and space-variable environmental and physiological factors may affect the net fractionation between synthesized compounds and ambient water. Following the work of Englebrecht and Sachs (2005), Schouten et al. (2006) investigated the effects of temperature $(T)$, salinity $(S)$, and growth rate $(\mu)$ on $\alpha_{\mathrm{K} 37 \mathrm{~s}-\text { water }}$ in batch cultures. Both $S$ and $\mu$, but not $T$, were reported to effect $\alpha_{\mathrm{K} 37 \mathrm{~s}-\text { water }}$ in the haptophytes E. huxleyi and G. oceanica, the two most prominent sources of these biomarkers in the modern ocean.

Although the apparent salinity effect could be beneficial, acting as an amplifier of the hydrologically-driven $\delta D_{\mathrm{K} 37 \mathrm{~s}}$ signal (Pahnke et al., 2007), its inclusion in the formulation of $\alpha_{\mathrm{K} 37 \mathrm{~s}-\text { water }}$ as a function of salinity adds another source of uncertainty to the proxy calibration (Rohling, 2007). The possible growth-rate effects identified by Schouten et al. (2006) would also be problematic for the paleosalinity application of sedimentary $\delta D_{\mathrm{K} 37 \mathrm{~s}}$ measurements. Variation in haptophyte growth rate cannot currently be constrained by proxy without temporal extrapolations of modern conditions or assumptions about paleo- $p \mathrm{CO}_{2}$ (van der Meer et al., 2008). Consequently, concerns over the convolution of growth-rate (Laws et al., 1995) and $p \mathrm{CO}_{2}$ effects (Jasper et al., 1994) on carbon-isotopic fractionation in alkenones have played a large part in undermining this measure's utility as a paleo- $p \mathrm{CO}_{2}$ proxy. Were growth-rate dependent stratigraphic variations in $\delta D_{\mathrm{K} 37 \mathrm{~s}}$ signal to appear down a core, they could not be deconvolved from changes in $\delta D_{\text {water }}$. For example, using the "ocean main sequence" $\delta^{18} \mathrm{O}_{\text {water }}$ versus salinity line $\left(\delta^{18} \mathrm{O}_{\text {water }} \approx 0.5 \mathrm{~S}-17\right.$, Craig and Gordon, $1965)$ and assuming a "meteoric" relationship between $\delta D$ and $\delta^{18} \mathrm{O}\left(\delta D_{\text {water }} \approx 8 \delta^{18} \mathrm{O}_{\text {water }}+10\right.$, Craig, 1961), a typical whole ocean salinity range of 32 to 37 would correspond to a $\delta D_{\text {water }}$ range of $\sim 2$ to $22 \%$ (vs. SMOW). Translated into a $\delta D_{\mathrm{K} 37 \mathrm{~s}}$ signal using the mean value of $\alpha_{\mathrm{K} 37 \mathrm{~s} \text {-water }}(0.790)$ reported by Schouten et al. (2006), $\delta D_{\mathrm{K} 37 \mathrm{~s}}$ measurements would span from $-208 \%$ o to $-193 \%$ o, a range of $\sim 15 \%$. Based on the data of Schouten et al. (2006), an oceanographically reasonable variation in haptophyte growth rate ( $\sim 0.2$ and 0.8 day $^{-1}$, Bidigare et al., 1997) would be asso- ciated with an $\alpha_{\mathrm{K} 37 \mathrm{~s}-\text { water }}$ range of 0.814 to 0.796 . Within

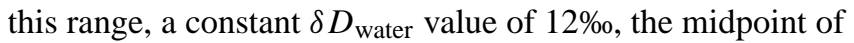
the $\delta D_{\text {water }}$ range above, would yield $\delta D_{\mathrm{K} 37 \mathrm{~s}}$ values falling anywhere between -176 and $-194 \%$. This $18 \%$ range is greater than the $15 \%$ range expected for changes in openocean salinity. If one accepts the salinity "amplification" effect as reported by Schouten et al. (2006), i.e. that $\alpha_{\mathrm{K} 37 \mathrm{~s}-\text { water }}$ varies from 0.799 to 0.815 between $S=32$ and $S=37$, then this salinity range would yield $\delta D_{\mathrm{K} 37 \mathrm{~s}}$ values between -200 and $-168 \%$, a $32 \%$ orange. This contrast is larger, but still on the same order as the $\sim 18 \%$ o variation potentially associated with growth rate. With the biological effects on fractionation factors this unconstrained (for a discussion of the further uncertainties in this sort of reconstruction due to variation in $\delta D_{\text {water }}$ vs. $S$ relationships, see Rohling, 2007), it is unlikely that $\delta D_{\mathrm{K} 37 \mathrm{~s}}$ measurements could provide unequivocal quantitative information about absolute changes in $\delta D_{\text {water }}$ for any oceanographic settings other than those characterized by the highest salinity contrasts, such as areas of periodic melt water discharge or variable river outflow (e.g. Friedman et al., 1964).

\subsection{The premise of alkenone $\delta D$ measurements as a physiological stress proxy}

If $\delta D_{\mathrm{K} 37 \mathrm{~s}}$ values are to provide an effective proxy for any paleoreconstruction purpose (salinity or otherwise), it is essential that the effects of variable growth conditions on isotopic fractionation be evaluated and constrained. Schouten et al. (2006) have lain the groundwork, demonstrating that variation in cell physiology plays a significant role in setting $\delta D_{\mathrm{K} 37 \mathrm{~s}}$ values. Although these effects clearly complicate use of $\delta D_{\mathrm{K} 37 \mathrm{~s}}$ measurements for paleosalinity reconstruction, is it possible that this physiological complication could be exploited for paleoceanographic advantage?

Analysis of the molecular composition of alkenones preserved in surface sediments off the west coast of South America led Prahl et al. (2006) to suggest that the fossil signatures are characteristic of stressed, rather than exponentially dividing cells. They hypothesized that stress, in this setting, is imposed by the exposure of cells to a combination of nutrient depletion (prior to sedimentation) and light deprivation (during the export of viable cells). These results echo those of Conte et al. (1995), who observed the same biochemical cues in suspended particulate matter from North Atlantic surface waters. Prahl et al. (2006) suggested that the effects these stresses have on the alkenone unsaturation index $\left(U_{37}^{K^{\prime}}\right)$ contribute to the several-degree-Celsius "scatter" in the linear, global core-top calibration for $U_{37}^{K^{\prime}}$ versus mean annual SST (maSST, Müller et al., 1998).

If the fossil alkenone record does not strictly reflect the molecular composition of exponentially dividing cells, then to what extent might the $\delta D$ composition of these biomarkers also deviate from that reported exclusively, so far, for cells harvested in the nutrient-replete, exponential growth 
phase? Given the recognized dependence of $\alpha_{\mathrm{K} 37 \mathrm{~s} \text {-water }}$ on growth conditions, one may expect that $\delta D_{\mathrm{K} 37 \mathrm{~s}}$ values would vary systematically from one biogeographical regime to another, as now seems to be the case for deviations of $U_{37}^{K^{\prime}}$ measurements from values predicted by the standard calibration curve (Prahl et al., 2009). If a significant difference in $\alpha_{\mathrm{K} 37 \mathrm{~s}-\text { water }}$ exists between cells in the exponential and nutrient stress-imposed stationary growth phases, deviation of $\delta D_{\mathrm{K} 37 \mathrm{~s}}$ measurements from expected values could provide a physiological context within which $U_{37}^{K^{\prime}}$ records may be interpreted more objectively.

\subsection{Analytical concerns}

In addition to environmental and physiological effects on actual isotopic fractionation, the effects of growth conditions on the molecular fingerprint of alkenones also pose a potential problem for the interpretation of $\delta D_{\mathrm{K} 37 \mathrm{~s}}$ measurements from field samples. While the chromatographic peaks of $\mathrm{C}_{37}$ alkenones are generally baseline-resolved when analyzed for molecular composition by gas chromatography (GC), the order-of-magnitude increase in sample size necessary for $\delta D$ analysis by gas chromatography-pyrolysis-isotope ratio mass-spectrometry (GC-P-IRMS) overloads capillary GC columns and results in unresolved peaks (D'Andrea et al., 2007). Consequently, alkenone-specific $\delta D$ measurements are now typically reported as an integrated signal (e.g. Englebrecht and Sachs, 2005; Schouten et al., 2006). Integrated values for $\delta D_{\mathrm{K} 37 \mathrm{~s}}$ include contributions from di- (K37:2), tri- (K37:3), and, if present, tetra-unsaturated (K37:4) components. This analytical concern is moot if all three compounds are isotopically identical. However, if these compounds are isotopically distinct, changes in $U_{37}^{K^{\prime}}$, such as those that occur during the onset of nutrient-imposed stationary growth (e.g., Prahl et al., 2003) or when growth temperature changes, would complicate interpretation of a measured $\delta D_{\mathrm{K} 37 \mathrm{~s}}$ value. To address this issue, D'Andrea et al. (2007) developed a manual silver-silica gel chromatographic method to separate alkenones according to their degree of unsaturation, and found K37:3 to be significantly more deuterium-depleted than K37:2 in samples of E. huxleyi. The fractionation factor calculated for the two com-

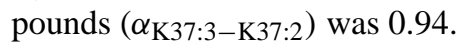

Existence of an isotopic offset between these two compounds has ramifications for down-core analyses. Given that 1) the measured $\delta D$ value of a combined $\mathrm{K} 37: 3$ and $\mathrm{K} 37: 2$ GC-P-IRMS peak (see Fig. 2) is defined by:

$\delta D_{\mathrm{K} 37 \mathrm{~s}}=\delta D_{\mathrm{K} 37: 3} f_{\mathrm{K} 37: 3}+\delta D_{\mathrm{K} 37: 2} f_{\mathrm{K} 37: 2}$

where $f$ is the fraction of $\mathrm{K} 37: 3$ or $\mathrm{K} 37: 2$ represented in the peak, 2) the isotopic contrast between these compounds is defined by:
$\alpha_{\mathrm{K} 37: 3-\mathrm{K} 37: 2}=\frac{\delta D_{\mathrm{K} 37: 3}+1000}{\delta D_{\mathrm{K} 37: 2}+1000}$

and 3) $U_{37}^{K^{\prime}}$ is defined as:

$U_{37}^{K^{\prime}}=\frac{[\mathrm{K} 37: 2]}{[\mathrm{K} 37: 3]+[\mathrm{K} 37: 2]}$

the isotopic difference between two K37s samples synthesized at two different temperatures, for example, can be calculated using the expression:

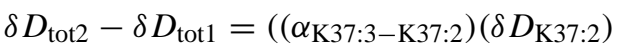

$$
\begin{aligned}
& +1000\left(\alpha_{\mathrm{K} 37: 3-\mathrm{K} 37: 2))}\left(U_{371}^{K^{\prime}}-U_{372}^{K^{\prime}}\right)\right. \\
& +\left(1000+\delta D_{\mathrm{K} 37: 2}\right)\left(U_{372}^{K^{\prime}}-U_{371}^{K^{\prime}}\right)
\end{aligned}
$$

For measured values of $\alpha_{\mathrm{K} 37: 3-\mathrm{K} 37: 2}(0.94)$ and $\delta D_{\mathrm{K} 37: 2}$ $(-188.1 \%$ o $)$ (D'Andrea et al., 2007) and a growthtemperature difference of $11^{\circ} \mathrm{C}$ (the range studied by Schouten et al., 2006) translated by standard means $\left(0.034 /{ }^{\circ} \mathrm{C}\right)$ into a $U_{37}^{K^{\prime}}$ difference, an $\sim+18 \%$ o difference in $\delta D_{\mathrm{K} 37 \mathrm{~s}}$ is calculated. Alternately, a change in $U_{37}^{K^{\prime}}$ of -0.2 , the magnitude associated with the onset of nutrient-depletion imposed senescence in E. huxleyi grown at $15^{\circ} \mathrm{C}$ (Prahl et al., 2003 ), would yield a $\delta D_{\mathrm{K} 37 \mathrm{~s}}$ difference of $\sim+9 \%$. A difference of this magnitude is well outside the precision typical of $\delta D_{\mathrm{K} 37 \mathrm{~s}}$ measurements (e.g. $\sim 6 \%$, Englebrecht and Sachs, 2005 ) and, thus, would be interpreted as significant. It could then be construed, when measured down-core, as caused by a change through time either in 1) growth temperature, 2) the mean growth phase of cells contributing to alkenone export, or 3) water composition.

One solution to the issue of unsaturation-specific fractionation is to separate alkenones prior to isotopic analysis and base interpretations on $\delta D$ values of a single compound. The additional chromatographic steps, however, even if automated, are labor and time intensive and raise concerns about fractionation effects associated with incomplete sample recovery (Smittenburg and Sachs, 2007). Measurement of $\delta D_{\mathrm{K} 37 \mathrm{~s}}$ and calculation of the $\delta D$ of a single compound by an isotope mass balance approach (algebraic rearrangement of Eqs. 2, 3, and 4):

$\delta D_{\mathrm{K} 37: 3, \text { calc }}=\frac{\left(\delta D_{\mathrm{K} 37 \mathrm{~s}}-\frac{1000 \cdot U_{37}^{K^{\prime}}}{\alpha_{\mathrm{K} 37: 3-\mathrm{K} 37: 2}}+1000 \cdot U_{37}^{K^{\prime}}\right)}{1-U_{37}^{K^{\prime}}+\frac{U_{37}^{K^{\prime}}}{\alpha_{\mathrm{K} 37: 2-\mathrm{K} 37: 2}}}$

is analytically simpler, but requires a well-constrained, con-

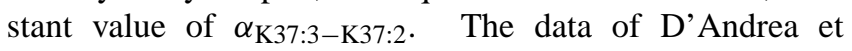
al. (2007) and Schwab and Sachs (2009) potentially support this premise. Nonetheless, the actual value of $\alpha_{\mathrm{K} 37: 3-\mathrm{K} 37: 2}$ remains in question.

\subsection{Objectives of this work}

The background presented above shows that use of $\delta D_{\mathrm{K} 37 \mathrm{~s}}$ as an unequivocal salinity proxy is, at best, currently problematic. Even if $\alpha_{\mathrm{K} 37 \mathrm{~s}-\text { water }}$ has a constant value of 0.790 (the 
mean value reported by Schouten et al., 2006), the current precision of $\delta D_{\mathrm{K} 37 \mathrm{~s}}$ measurements $( \pm 3$ to $5 \%, 1 \sigma)$ corresponds to an uncertainty in salinity reconstructions of $\sim \pm 1.0$ to 1.6 units. This assumes the meteoric $\delta^{18} \mathrm{O} / \delta D$ relationship and the ocean main sequence $\delta^{18} \mathrm{O} / \mathrm{S}$ relationship are both known with zero uncertainty. This hypothetical bestcase scenario poses a serious impediment given the small salinity variations typically of interest in open-ocean paleoceanographic studies (e.g. de Vernal et al., 2000).

However, the physiological factors that may affect $\delta D_{\mathrm{K} 37 \mathrm{~s}}$ values are themselves valid targets for paleoceanographic inquiry. Prior work suggests the physiological growth status of cells contributing to the export of alkenones from the euphotic zone plays an important role in fine-tuning the quantitative nature of the sedimentary $U_{37}^{K^{\prime}}$ record (Conte et al., 1995; Prahl et al., 2006). However, there is, as of yet, no defined method for objectively quantifying variation in stress effects on $U_{37}^{K^{\prime}}$ values measured down-core. In light of results from Schouten et al. (2006), compound-specific hydrogenisotopic data could provide such a tool, constraining some of the more significant non-thermal impacts on the $U_{37}^{K^{\prime}}$-derived temperature record.

Two important sets of questions that guided our laboratory-based experimental study were:

1. Is $\alpha_{\mathrm{K} 37: 3-\mathrm{K} 37: 2}$ a constant value in cells transitioning from an exponential to a nutrient-stress imposed stationary growth phase?

2. Does a difference in the hydrogen isotopic fractionation associated with alkenone biosynthesis exist between exponential and stationary growth phases? If so, what is the cause of the variation in $\alpha_{\mathrm{K} 37 \mathrm{~s}-\text { water }}$ ?

\section{Methods}

\subsection{Algal cultures}

Emiliania huxleyi (non-calcifying strain CCMP 1742) was batch cultured in duplicate isothermally $\left(15^{\circ} \mathrm{C}\right)$ under coolwhite light $\left(\sim 70 \mu \mathrm{Ein} / \mathrm{m}^{2} \mathrm{~s}, 12 \mathrm{~h}\right.$ light $/ 12 \mathrm{~h}$ dark cycle $)$ in $\mathrm{f} / 20$ media $(\sim 32$ salinity). Duplicate cultures from the same stock of E. huxleyi CCMP 1742 were grown isothermally $\left(18^{\circ} \mathrm{C}\right)$ under constant, cool-white light $\left(\sim 80 \mu \mathrm{Ein} / \mathrm{m}^{2} \mathrm{~s}\right)$ in enriched Ocean Station PAPA seawater at the University of British Columbia (Canada). This medium contained $\sim 300 \mu \mathrm{M}$ nitrate, $\sim 10 \mu \mathrm{M}$ phosphate, $\sim 32$ salinity, and Aquil-standard additions of trace metals with $100 \mu \mathrm{M}$ EDTA (Maldonado et al., 2006). Gephyrocapsa oceanica (calcifying strain PZ3-1) was batch cultured isothermally at three different temperatures $\left(17^{\circ}, 21^{\circ}\right.$, and $\left.25^{\circ} \mathrm{C}\right)$ in media (salinity $\sim 32$ ) equivalent to $\mathrm{K} / 8$ with a soil extract addition (https: //ccmp.bigelow.org/node/81) at Station Biologique Roscoff (France). In each case, cool-white light was supplied at $\sim 150 \mu \mathrm{Ein} / \mathrm{m}^{2} \mathrm{~s}$ on a $14 \mathrm{~h}$ light $/ 10 \mathrm{~h}$ dark cycle.
For all experiments, cell counts were conducted daily to monitor the progression of growth and establish the average growth rate (Fig. 1). "Exponential" phase cells were sampled during the log-linear portion of each growth curve. "Stationary" phase cells were sampled after the cessation of cell division. Cell sampling was conducted in duplicate for analysis of the molecular and $\delta D$ composition of alkenones. Duplicate samples of the culture media were also collected from the filtrate at each cell harvest for analysis of $\delta D_{\text {water }}$ and nutrients. Sampling points for each experiment are identified on the growth curves shown in Fig. 1.

\subsection{Sample preparation for molecular and isotopic characterization}

\subsubsection{Alkenone extraction and purification}

Total lipids were extracted from the cell samples following a standard procedure (Prahl et al., 1989), modified for automated solvent extraction using a Dionex ASE-200. All samples from the E. huxleyi cultures were saponified in ethanolic KOH (Christie, 2003) to remove alkenoates. Since the alkenoate content of the G. oceanica samples was negligible, they were not saponified. However, all G. oceanica samples were adducted with urea (Christie, 2003) to remove a series of polysiloxane contaminants which were present and otherwise would have interfered with the alkenone analysis.

\subsubsection{Unsaturation-specific separation}

One of the duplicate alkenone samples from each harvest point of the E. huxleyi cultures was separated into di- and tri-unsaturated fractions using argentation chromatography (Nikolova-Damyanova, 1992). The tetra-unsaturated $\mathrm{C}_{37} \mathrm{ke}-$ tone (K37:4) was a very minor component $(<3 \%$ of the total $\mathrm{C}_{37}$ compounds) in all samples. Initially, the exact protocol described by D'Andrea et al. (2007) was used, but clean separation of K37:2 and K37:3 could not be obtained. A much smaller increase in solvent strength (100\% dichloromethane (DCM) to $10 \%$ ethyl acetate (EtOAc) in DCM) than reported (10 to $30 \%$ EtOAc in DCM) was required to begin eluting the more unsaturated compounds and achieve complete separation. Consequently, a total volume of solvent 10x greater than that reported by D'Andrea et al. (2007) had to be run through the columns.

\subsubsection{Cryodistillation of water}

Prior to $\delta D$ analysis using a thermal-conversion elemental analyzer coupled to an isotope ratio mass spectrometer (TCEA-IRMS), samples of culture media water were quantitatively cryodistilled in triplicate. This preparative step was taken to eliminate salt from the water samples and prevent fouling of the TCEA pyrolysis column. A published method (West et al., 2006) for quantitatively extracting water from leaf and soil samples using a vacuum manifold was modified 
for use with whole-water samples. The key modification was replacement of the straight extraction tubes with similar ones ( $14 \mathrm{~cm}$ by $1 \mathrm{~cm}$ i.d.) containing a bulb $(2.5 \mathrm{~cm}$ i.d.) at the closed end. This modification eliminated a problem with sample processing caused by the buildup of pressure in the frozen sample when warmed under vacuum and distilled from one tube to the other. Distilled samples, stored in crimp-top autosampler vials until analysis, were shown to be isotopically identical to their undistilled counterparts to well within the $1.9 \%$ mean standard deviation of replicate distillations (see Sect. 2.4.1).

\subsection{Molecular characterization by GC-FID}

All isolated alkenone fractions were characterized compositionally and quantified by gas chromatography with flame ionization detection (GC-FID, Prahl et al., 1989). Cellular alkenone concentrations are reported as values corrected for recovery (typically 80-90\%) of hexatriacontan-2one (K36:0). K36:0 is a reference standard added to each sample prior to extraction with the ASE-200. Percent recovery for the unsaturation-specific isolates is reported as percent of each compound ( $\mathrm{K} 37: 2$ or $\mathrm{K} 37: 3$ ) relative to the amount quantified in the total $\mathrm{C}_{37}$ alkenone sample prior to separation by argentation chromatography.

\subsection{Isotopic analysis}

$\delta D$ analysis of $\mathrm{C}_{37}$ alkenones and water was performed using a ThermoQuest-Finnigan Delta Plus XL isotope ratio mass spectrometer operated in continuous flow mode. Using ISODAT software, " $\mathrm{H}_{3}^{+}$" correction factors (Sessions et al., 1999) were determined at the beginning of each day using eight sequential $\mathrm{H}_{2}$ reference gas injections of increasing partial pressure. Values ranged between $\sim 3$ and $\sim 7 \mathrm{ppm} / \mathrm{nA}$. All $\delta D$ values are reported versus Standard Mean Ocean Water (SMOW).

\subsection{1 $\delta D$ analysis of water in culture media}

Values for $\delta D_{\text {water }}$ in all distilled samples were determined using a Thermo-Electron TCEA-IRMS equipped with a Finnigan-MAT A200S liquid autosampler. The instrument was configured and operated as specified in the manual for liquid samples. Each vial was sampled using one "memory clearing" cleaning step as specified by a procedure from the Arizona State University Keck Foundation Laboratory for Environmental Biogeochemistry (http://kfleb.asu.edu), followed by three replicate $1 \mu \mathrm{L}$ sample injections. $\delta D_{\text {water }}$ values for each sample injection were calculated against the mean of two $\mathrm{H}_{2}$ reference gas injections made prior to the elution of the analyte peak in each run. For each batch of samples analyzed, the reference gas was standardized against three working reference waters (HOTSW $=-2.94 \% \circ \pm 0.36$; LROSS $=-71.84 \% \circ \pm 0.63$; WAIS3 $=-265.93 \% \circ \pm 0.43$, uncertainties given as standard errors of the mean, SEM, $n=9$ )
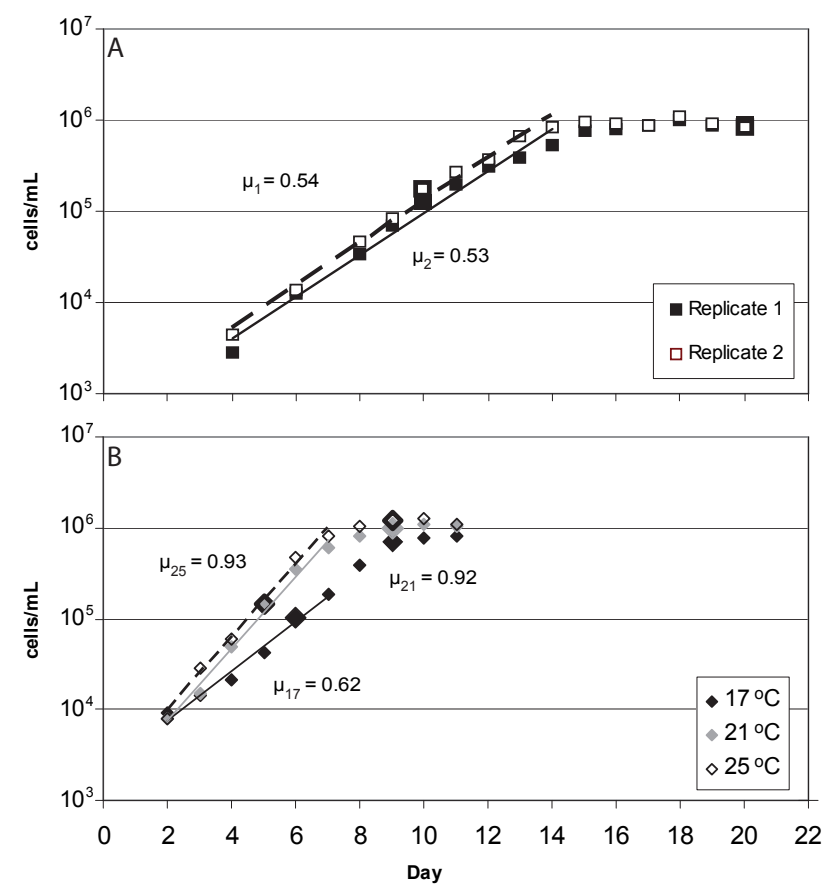

Fig. 1. Growth curves for batch cultures of (A) E. huxleyi $\left(15^{\circ} \mathrm{C}\right.$ cultures) and (B) G. oceanica. Growth rates $\left(\mu\right.$, day $\left.{ }^{-1}\right)$, derived from linear fits to the exponential portion of each curve, are denoted on the plots. The "exponential" and "stationary" growth phase time points when cell and water samples were collected are identified on each plot by the enlarged symbols.

that had been calibrated using three working reference materials provided by William Rugh (National Health and Environmental Effects Research Laboratory, US-EPA, Corvallis, OR). The reference materials from the EPA laboratory had, in turn, been calibrated versus the GISP, SLAP, and SMOW primary reference materials from National Institute of Standards and Technology (www.nist.gov). The standard error of the mean of the working reference materials during the sample runs ( 2 vials of each standard $\times 3$ injections each) was $0.47 \%$, and the precision of the measurements (taken as the mean standard deviation of the reference compounds) was $\pm 2.5 \%$ o. The mean standard deviation of 25 different triplicate sample distillations was $1.9 \%$.

Water samples from the G. oceanica culture experiments were lost due to breakage during shipment from France. Fractionation factors for alkenone samples from these cultures are calculated assuming a $\delta D_{\text {water }}$ of $0 \%$. This value is chosen as an estimate because the medium was prepared using water from the English Channel with a salinity of 32 . The exact choice of the value is not overly critical to our assessment of the direction and magnitude of growth-phase effects, however, as variability in $\alpha_{\mathrm{K} 37 \mathrm{~s}-\text { water }}$ determinations is driven largely by variability in $\delta D_{\mathrm{K} 37 \mathrm{~s}}$ values. $\delta D_{\text {water val- }}$ ues ranging between 2 and $-8 \%$ may be used in the calculation of $\alpha_{\mathrm{K} 37 \mathrm{~s}-\text { water without shifting the results outside of a }}$ \pm 0.005 range. 


\subsection{2 $\delta D$ analysis of alkenones}

The $\delta D$ of the alkenones was analyzed by GC-P-IRMS. Just prior to analysis, samples were dissolved in a suitable volume of toluene to ensure that a $2 \mu \mathrm{L} \mathrm{GC}$ injection introduced $\sim 500 \mathrm{ng}$ of the minor $\mathrm{C}_{37}$ component. An exception was made for the G. oceanica samples harvested from the $25^{\circ} \mathrm{C}$ batch culture experiment because there was not enough of the minor component, $\mathrm{K} 37: 3$, to make this approach practical. In this case, the dilution volume was chosen to ensure $500 \mathrm{ng}$ injections of the major component, K37:2. Samples, coinjected with $1 \mu \mathrm{L}$ of an $\mathrm{n}$-alkane working standard (530 $\mathrm{ng} \mathrm{nC}_{36} / \mu \mathrm{L}$, $330 \mathrm{ng} \mathrm{nC}_{37} / \mu \mathrm{L}$ ), were chromatographically separated using an HP6890 GC equipped with a cool on-column injector and a SGE BF5 (30 $\mathrm{m} \times 0.32 \mathrm{~mm}$ i.d., $1.0 \mu \mathrm{m}$ film) column.

The GC was operated at a constant helium carrier gas flow rate $(2.5 \mathrm{~mL} / \mathrm{min})$. Compound separations were achieved by temperature programming $\left(80-270^{\circ} \mathrm{C}\right.$ at $10^{\circ} \mathrm{C} / \mathrm{min}, 270$ $320^{\circ} \mathrm{C}$ at $5^{\circ} \mathrm{C} / \mathrm{min}, 43 \mathrm{~min}$ hold at $320^{\circ} \mathrm{C}$ ). The alumina pyrolysis reactor $(32 \mathrm{~cm} \times 0.5 \mathrm{~mm}$ i.d.), installed in the ThermoFinnigan GC-TC interface, was maintained at $1450^{\circ} \mathrm{C}$. Upon initial use, the reactor was pre-conditioned (graphitized) by passing several $1 \mu \mathrm{L}$ injections of isooctane through it. If necessary, such pre-conditioning was repeated until measured standard values stabilized. Figure 2 shows an example chromatogram from GC-P-IRMS analysis of an alkenone sample.

Isotopic values for $\mathrm{C}_{37}$ alkenones were calculated versus the coinjected $\mathrm{nC}_{36}$ and $\mathrm{nC}_{37}$ alkane and $\mathrm{C}_{36}$ ketone (K36:0) reference materials. "Known" values of these working references were determined by standardization through co-injection with "Mixture B", a 15 compound mixture of n-alkanes obtained from A. Schimmelmann (Indiana University). The average of these standardization analyses performed over 10 months yielded the following 'known' values: $\mathrm{nC}_{36}=-265.1 \% \circ \pm 0.8$, $\mathrm{nC}_{37}=-217.7 \%$ o $\pm 0.8, \mathrm{~K} 36: 0=-186.5 \pm 0.9 \%$ (uncertainties reported as SEM, $n=25$ ). The standard error of the mean (SEM) of the working reference materials during the sample runs $(n=18)$ was $0.9 \%$, and the precision of the measurements (taken as the mean standard deviation of the reference compounds) was $\pm 3.9 \%$. The mean standard deviation of all sets of replicate samples was $2.0 \%$.

For each day of sample analysis, a linearity correction for the mass spectrometer was determined by linear regression of measured versus known $\delta D$ values for each n-alkane in a "Mixture B" standardization run. This correction was then applied to each sample measurement using the equation:

$\delta D_{\text {corrected }}=\frac{\delta D_{\text {uncorrected }}-b}{m}$

where $m$ and $b$ are the slope and intercept, respectively, of the linear regression. The magnitude of the applied correction averaged $1.3 \%$ and never exceeded $2.7 \%$. In Table 1 , all $\delta D$ values for alkenones are reported as the mean of two or three replicate injections of the same sample.

\section{Results}

Table 1 summarizes the results of the molecular and hydrogen isotopic analysis of samples from the E. huxleyi and $G$. oceanica batch culture experiments.

\subsection{Molecular characterization}

Total $\mathrm{C}_{37}$ alkenone abundance $(\mathrm{K} 37 \mathrm{~s}, \mathrm{pg} / \mathrm{cell})$, alkenone unsaturation values $\left(U_{37}^{K^{\prime}}\right)$ and combined $\mathrm{C}_{37}$ as a percentage of total $\mathrm{C}_{37-39}$ alkenone abundance (\%K37) measured in the E. huxleyi samples grown at $15^{\circ} \mathrm{C}$ followed trends expected for cells transitioning from the exponential to the stationary phase of growth (Table 1). Cellular K37s increased by a factor of three upon exposure to nutrient depletion, in keeping with their purported use as an energy storage product (e.g. Elgroth et al., 2005). The $\sim 0.1$ unit decrease in $U_{37}^{K^{\prime}}$ observed for the stationary-phase samples compares well with the shift documented for exposure of this strain to isothermal nutrient stress at this growth temperature (Prahl et al., 2003). Likewise, while \%K37 values for the exponentialphase samples $(\sim 55 \%)$ were lower than those previously reported for nutrient-replete samples $(\sim 65 \%)$, the $\sim 5 \%$ decrease observed in the stationary-phase samples is consistent with the previously-documented impact of nutrient depletion on this property. The same pattern of relative shifts in the molecular fingerprint was documented in the early exponential and late exponential-phase samples harvested from the grow-out experiment conducted at UBC using the same culture stock of E. huxleyi (Table 1).

Results from analysis of the G. oceanica samples generally paralleled those for E. huxleyi (Table 1). Cellular concentrations of $\mathrm{K} 37 \mathrm{~s}$ did not increase as significantly, however, and an increase was only apparent in the $17^{\circ} \mathrm{C}$ and $21^{\circ} \mathrm{C}$ experiments. A decrease in $U_{37}^{K^{\prime}}$ upon the transition of cells from the exponential to the stationary growth phase was also seen $\left(-0.05,-0.06,-0.01\right.$ units for the $17^{\circ}, 21^{\circ}, 25^{\circ} \mathrm{C}$ treatments, respectively). The magnitude of the decrease, smaller than that observed for E. huxleyi, was likely due to harvesting the cells at the onset of stationary phase and not at a later point in time (Fig. 1). The apparent lack of change in $U_{37}^{K^{\prime}}$ for cells from the $25^{\circ} \mathrm{C}$ experiment may reflect the fact that values for the alkenone unsaturation index at this growth temperature are very nearly unity, the maximum possible for this index. Finally, the magnitude of the decrease in \%K37 values from exponential to stationary phase growth also roughly paralleled the pattern expected for E. huxleyi (Prahl et al., 2006). 
Table 1. Results from Growth-Phase Experiments with E. huxleyi CCMP 1742 and G. oceanica PZ3-1.

\begin{tabular}{|c|c|c|c|c|c|c|c|c|c|c|c|c|c|c|c|c|}
\hline $\begin{array}{l}\text { Sampling } \\
\text { Phase }\end{array}$ & $\begin{array}{l}\text { Replicate } \\
\text { Culture }\end{array}$ & $\begin{array}{c}\text { Growth } \\
\text { Temperature } \\
\left({ }^{\circ} \mathrm{C}\right)\end{array}$ & $\begin{array}{c}\text { Growth } \\
\text { Rate } \\
\left(\text { day }^{-1}\right) \\
\end{array}$ & $\begin{array}{c}{\left[\mathrm{NO}_{3}^{-}\right]+\left[\mathrm{NO}_{2}^{-}\right]} \\
(\mu \mathrm{mol} / \mathrm{L})\end{array}$ & $\begin{array}{c}{\left[\mathrm{PO}_{4}^{3-}\right]} \\
(\mu \mathrm{mol} / \mathrm{L})\end{array}$ & $\%$ Recovery $^{\mathrm{b}}$ & $\begin{array}{l}\text { Uk'37 } \\
( \pm 0.01)\end{array}$ & $\%$ K37 & $\begin{array}{c}\mathrm{K} 37 \mathrm{~s} / \mathrm{cell} \\
(\mathrm{pg} / \mathrm{cell})\end{array}$ & $\begin{array}{c}\delta D_{\mathrm{K} 37} \\
(\% \circ \text { vs. SMOW) }\end{array}$ & \pm (SEM) & $n$ & $\begin{array}{c}\delta D_{\text {water }} \\
(\% o \text { vs. SMOW) }\end{array}$ & $\begin{array}{c} \pm(\text { SEM }) \\
(n=9)\end{array}$ & $\begin{array}{c}\alpha_{\mathrm{K} 37-\text { water }^{\mathrm{c}}} \\
( \pm 0.004)\end{array}$ & $\begin{array}{l}\alpha_{\mathrm{K} 37: 3-\mathrm{K} 37: 2} \\
( \pm 0.007)\end{array}$ \\
\hline \multicolumn{17}{|c|}{ E. huxleyi CCMP 1742 Cultures } \\
\hline \multirow{10}{*}{ Exponential } & Culture 1 & 15 & 0.58 & 74.4 & 2.9 & 68 & 0.41 & 55 & 0.44 & -186.4 & 0.5 & 3 & -8.7 & 0.6 & 0.821 & \\
\hline & Replicate $^{\mathrm{a}}$ & & 0.58 & & & 72 & 0.40 & 54 & 0.44 & & & & & & & \\
\hline & $\mathrm{K} 37: 2$ & & & & & 89 & & & & -171.0 & 0.5 & 2 & $" ”$ & & 0.836 & \\
\hline & $\mathrm{K} 37: 3$ & & & & & 72 & & & & -184.7 & 4.5 & 3 & $" ”$ & & 0.822 & 0.983 \\
\hline & Reconstructed Total K37 & & & & & & & & & -179.3 & 2.7 & & $" ”$ & & 0.828 & \\
\hline & Culture 2 & 15 & 0.56 & 66.2 & 2.3 & 76 & 0.41 & 55 & 0.46 & -191.0 & 0.1 & 2 & -9.2 & 0.9 & 0.816 & \\
\hline & Replicate $^{\mathrm{a}}$ & & 0.56 & & & 77 & 0.41 & 55 & 0.45 & & & & 5.2 & 0.7 & 0.010 & \\
\hline & $\mathrm{K} 37: 2$ & & & & & 91 & & & & -178.8 & 0.2 & 2 & $" ”$ & & 0.829 & \\
\hline & K37:3 & & & & & 67 & & & & -190.9 & 1.2 & 3 & $" ”$ & & 0.817 & 0.985 \\
\hline & Reconstructed Total $K 37$ & & & & & & & & & -185.9 & 0.7 & & $" ”$ & & 0.822 & \\
\hline \multirow[t]{10}{*}{ Stationary } & Culture 1 & 15 & & 0.3 & 0.31 & 59 & 0.30 & 52 & 1.3 & -215.3 & 2.5 & 2 & -7.7 & 1.1 & 0.791 & \\
\hline & Replicate $^{\mathrm{a}}$ & & & & & 75 & 0.29 & 50 & 1.5 & & & & & & & \\
\hline & $\mathrm{K} 37: 2$ & & & & & 94 & & & & -200.9 & 2.3 & 2 & $" ”$ & & 0.805 & \\
\hline & $\mathrm{K} 37: 3$ & & & & & 85 & & & & -221.4 & 2.0 & 2 & $" ”$ & & 0.785 & 0.974 \\
\hline & Reconstructed Total K37 & & & & & & & & & -215.5 & 1.6 & & $" ”$ & & 0.791 & \\
\hline & Culture 2 & 15 & & 0.6 & 0.28 & 78 & 0.30 & 52 & 1.4 & -212.9 & 1.5 & 2 & -7.6 & 0.3 & 0.793 & \\
\hline & Replicate $^{\mathrm{a}}$ & & & & & 72 & 0.29 & 50 & 1.6 & & & & & & & \\
\hline & $\mathrm{K} 37: 2$ & & & & & 91 & & & & -198.9 & 1.1 & 2 & $" ”$ & & 0.807 & \\
\hline & $\mathrm{K} 37: 3$ & & & & & 86 & & & & -222.1 & 0.2 & 2 & "” & & 0.784 & 0.971 \\
\hline & Reconstructed Total $K 37$ & & & & & & & & & -215.3 & 0.4 & & $" ”$ & & 0.791 & \\
\hline \multicolumn{17}{|c|}{ UBC E. huxleyi CCMP 1742 Cultures } \\
\hline \multirow[t]{2}{*}{ Mid-Log } & A & 18 & 0.61 & & & & 0.36 & 64 & 1.3 & -189.8 & 0.2 & 2 & & & 0.817 & \\
\hline & B & 18 & 0.62 & 308 & 9.7 & & 0.37 & 64 & 3.0 & -189.9 & 0.3 & 2 & & & 0.817 & \\
\hline \multirow[t]{2}{*}{ Late-Log } & A & 18 & & & & & 0.30 & 63 & 4.5 & -204.8 & 2.8 & 3 & & & 0.802 & \\
\hline & B & 18 & & 244 & 5.8 & & 0.30 & 62 & 2.8 & -203.0 & 0.2 & 2 & & & 0.803 & \\
\hline \multicolumn{17}{|c|}{ G. oceanica PZ3-1 Cultures } \\
\hline \multirow[t]{3}{*}{ Exponential } & Culture 1 & 17 & 0.62 & & & & 0.44 & 55 & 0.60 & -190.9 & 0.9 & 2 & & & 0.809 & \\
\hline & Culture 2 & 21 & 0.92 & & & & 0.74 & 56 & 0.82 & -204.6 & 0.1 & 2 & & & 0.795 & \\
\hline & Culture 3 & 25 & 0.93 & & & & 0.99 & 59 & 2.0 & -229.9 & 1.4 & 2 & & & 0.770 & \\
\hline \multirow[t]{3}{*}{ Stationary } & Culture 1 & 17 & & & & & 0.38 & 48 & 0.78 & -213.2 & 5.4 & 2 & & & 0.787 & \\
\hline & Culture 2 & 21 & & & & & 0.68 & 41 & 1.2 & -235.5 & 0.2 & 2 & & & 0.765 & \\
\hline & Culture 3 & 25 & & & & & 0.98 & 53 & 1.1 & -262.6 & 0.4 & 2 & & & 0.737 & \\
\hline
\end{tabular}

a Values measured on samples prior to separation by argentation chromatography.

b Values for total K37s samples are calculated as described in Sect. 2.3. Percent recovery for the K37:2 and K37:3 isolates is specific to the argentation chromatographic procedure.

c Assuming $\delta D_{\text {water }}=-7.9 \pm 2.5 \%$ for the UBC E. huxleyi cultures (average value from previous experiments using the same medium); assuming $\delta D_{\text {water }}=0 \pm 5 \%$ o for $G$. oceanica samples due to loss of water samples (see Sect. 2.4.1). Uncertainty for G. oceanica estimates is approximately \pm 0.006 .

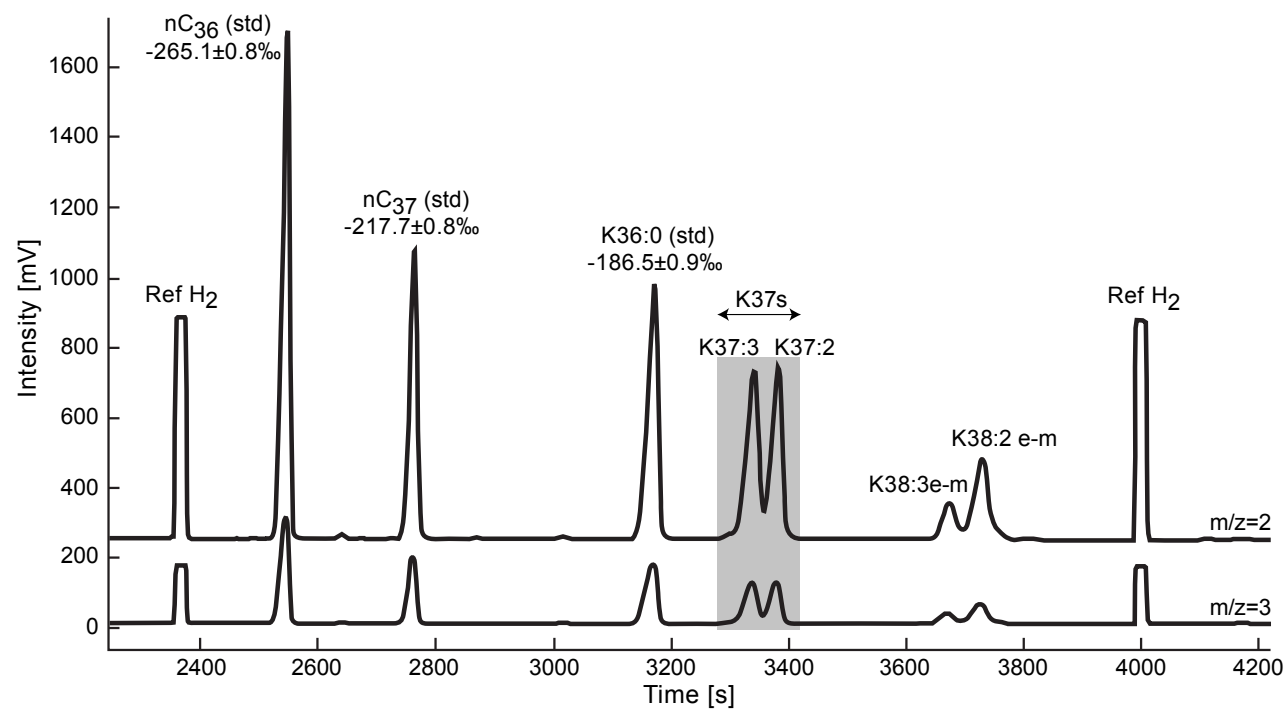

Fig. 2. Example chromatogram from compound-specific $\delta D$ analysis of alkenones by GC-P-IRMS. For total $\mathrm{C}_{37}$ alkenone (K37s) measurements, an isotope ratio was determined by integrating across the unresolved K37:3 and K37:2 peaks (shaded area). "K38:3e-m" and "K38:2e-m" labels denote peaks comprised of the unresolved ethyl and methyl $\mathrm{C}_{38}$ ketones. 


\subsection{Isotopic characterization}

The $\delta D_{\text {water }}$ for the $E$. huxleyi cultures was essentially invariant between the exponential and stationary sampling points, averaging $-8.3 \pm 0.4 \%$ o (Table 1). Uncertainties in $\delta D$ values are given as SEMs. $\delta D_{\mathrm{K} 37 \mathrm{~s}}$ values measured on unseparated samples of $E$. huxleyi from the exponential growth phase averaged $-188.7 \pm 0.3 \%$, yielding an $\alpha_{\mathrm{K} 37 \mathrm{~s} \text {-water }}$ of $0.819 \pm 0.003$. Note that the uncertainty provided for calculated values of $\alpha$ is based on the generally more-conservative precision estimates (mean $\sigma$ of standards) provided above for $\delta D_{\text {water }}, \pm 2.5 \%$ o, and $\delta D_{\mathrm{K} 37 \mathrm{~s}}, \pm 3.9 \%$ o, rather than the SEMs associated with individual, low-replication samples. The average $\delta D_{\mathrm{K} 37 \mathrm{~s}}$ values measured in stationary-phase samples was $-214.1 \pm 1.4 \%$ o, corresponding to an average $\alpha_{\mathrm{K} 37 \mathrm{~s} \text {-water }}$ of $0.792 \pm 0.003$. Figure 3 illustrates the magnitude and consistency of the difference in $\alpha_{\mathrm{K} 37 \mathrm{~s} \text {-water }}$ between exponential and stationary phase cells for replicate culture experiments.

Isolated K37:2 and K37:3 exhibited similar shifts in $\delta D$ composition between the exponential and stationary growth phase samples. Furthermore, K37:3 was, in all cases, the more deuterium-depleted of the two compounds. For $E$. huxleyi sampled in the exponential growth phase, the mean $\delta D_{\mathrm{K} 37: 2}(-174.9 \pm 0.3 \%$ o $)$ and $\delta D_{\mathrm{K} 37: 3}(-187.8 \pm 2.3 \%$ o values yielded an average $\alpha_{\mathrm{K} 37: 3-\mathrm{K} 37: 2}$ for the two cultures of $0.984 \pm 0.005$. In the stationary growth phase samples, greater isotopic fractionation was apparent between compounds (average $\alpha_{\mathrm{K} 37: 3-\mathrm{K} 37: 2}$ for both cultures of $0.973 \pm 0.005)$ given the mean measurements of $\delta D_{\mathrm{K} 37: 2}$ $\left(-199.9 \pm 1.3 \%\right.$ ) and $\delta D_{\mathrm{K} 37: 3}(-221.7 \pm 1.0 \%)$. Figure 3 has been annotated to illustrate the differences in assessed values of $\alpha_{\mathrm{K} 37: 3-\mathrm{K} 37: 2}$ for the individual exponential and stationary growth phase samples.

An isotopic mass balance approach was used to reconstruct the unseparated $\delta D_{\mathrm{K} 37 \mathrm{~s}}$ value in the four argentation chromatography experiments (Table 1 ). This exercise was possible given measured values of $U_{37}^{K^{\prime}}, \delta D_{\mathrm{K} 37: 2}, \delta D_{\mathrm{K} 37: 3}$ and the equation:

$\delta D_{\mathrm{K} 37 \mathrm{~s}}=\delta D_{\mathrm{K} 37: 3}\left(1-U_{37}^{K^{\prime}}\right)+\delta D_{\mathrm{K} 37: 2} U_{37}^{K^{\prime}}$

Reconstructions based on results for both sets of exponentialphase measurements yielded an average value for $\alpha_{\mathrm{K} 37 \mathrm{~s}-\text { water }}$ $(0.825 \pm 0.003)$ that is similar, but not statistically identical (two-sided student's t-test $p=0.18$ ), to the average measured value $(0.819 \pm 0.003)$. Reconstructions for both sets of stationary-phase measurements yielded an average $\alpha_{\mathrm{K} 37 \mathrm{~s}-\text { water }}$ value $(0.791 \pm 0.003)$ which is identical (twosided $p=0.77)$ to the average measured value $(0.792 \pm 0.003)$. Again, these findings are summarized in Fig. 3.

In the E. huxleyi batch culture grow-out experiment conducted at UBC, a comparable shift was seen in the mean $\delta D_{\mathrm{K} 37 \mathrm{~s}}$ value between early exponential $(-189.9 \pm 0.2 \%$ o $)$ and late exponential $(-203.9 \pm 1.5 \%$ ) growth phase samples (Table 1). This finding substantiates the idea that there is indeed a phase-dependant process affecting net alkenone biosynthetic fractionation in this organism. Furthermore, the phenomenon is not restricted to this species of alkenoneproducing haptophyte. A similar trend in deuterium depletion is apparent in $\delta D_{\mathrm{K} 37 \mathrm{~s}}$ measurements for G. oceanica when the exponential and stationary growth phase samples are compared. This feature was characteristic of results from all three temperature treatments. The decrease in $\delta D_{\mathrm{K} 37 \mathrm{~s}}$ between growth phases yielded shifts in estimated

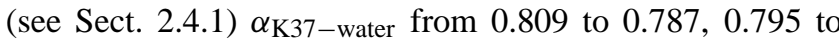
0.765 , and 0.770 to $0.737( \pm \sim 0.006)$ for the $17^{\circ} \mathrm{C}, 21^{\circ} \mathrm{C}$, and $25^{\circ} \mathrm{C}$ cultures, respectively. A scatter plot of these data suggests the decline in $\alpha_{\mathrm{K} 37 \mathrm{~s}-\text { water }}$ with increasing temperature is systematic (Fig. 4). Notably, results obtained from the experiments with E. huxleyi appear to lie along the trends defined by the G. oceanica samples.

\section{Discussion}

\subsection{Unsaturation-specific fractionation}

Argentation chromatography confirms the original finding of D'Andrea et al. (2007) that a significant isotopic offset exists between K37:3 and K37:2, with the tri-unsaturated compound being the more depleted in deuterium. In addition, an initial view of the results suggest that the fractionation between the two compounds $\left(\alpha_{\mathrm{K} 37: 3-\mathrm{K} 37: 2}\right)$ is greater in the stationary $(\sim 0.973)$ than in exponential $(\sim 0.984)$ growth phase (Fig. 3). While both compounds are more deuteriumdepleted in the stationary growth phase, the shift appears greater for K37:3. The apparent difference in the degree of fractionation between these two compounds with growth phase, however, may be an analytical artifact.

The likelihood of this artifact is evidenced by Fig. 3 . Despite possible statistical similarity of the "reconstructed" $\alpha_{\mathrm{K} 37 \mathrm{~s}-\text { water }}$ values derived from the separated, exponential growth phase samples and their unseparated counterparts ( $p=0.18$, Sect. 3.2), results for the individual compounds do not bracket the corresponding total K37s values as would be required to satisfy isotopic mass-balance requirements. Results from the stationary growth phase samples, however, do. Closer examination of results of the argentation chromatography separations suggests a cause for the discrepancy. The isotopic difference between both K37:2 and K37:3 and their associated, unseparated K37s samples were calculated $(\Delta \delta D)$ to normalize against the effect of changing overall isotopic composition with growth phase. The $\Delta \delta D$ results are plotted in Fig. 5 versus percent recovery for each compound from the argentation chromatography procedure. Given that unseparated $\delta D_{\mathrm{K} 37 \mathrm{~s}}$ measurements are comprised only of contributions from K37:2 and K37:3, isotopic mass balance requires that these two compounds plot on opposite sides of the zero-difference line. If the tight vertical clustering of all $\Delta \delta D_{\mathrm{K} 37: 2}$ values (Fig. 5) indicates that these data are reliable, then the $\Delta \delta D_{\mathrm{K} 37: 3}$ values for the exponential 


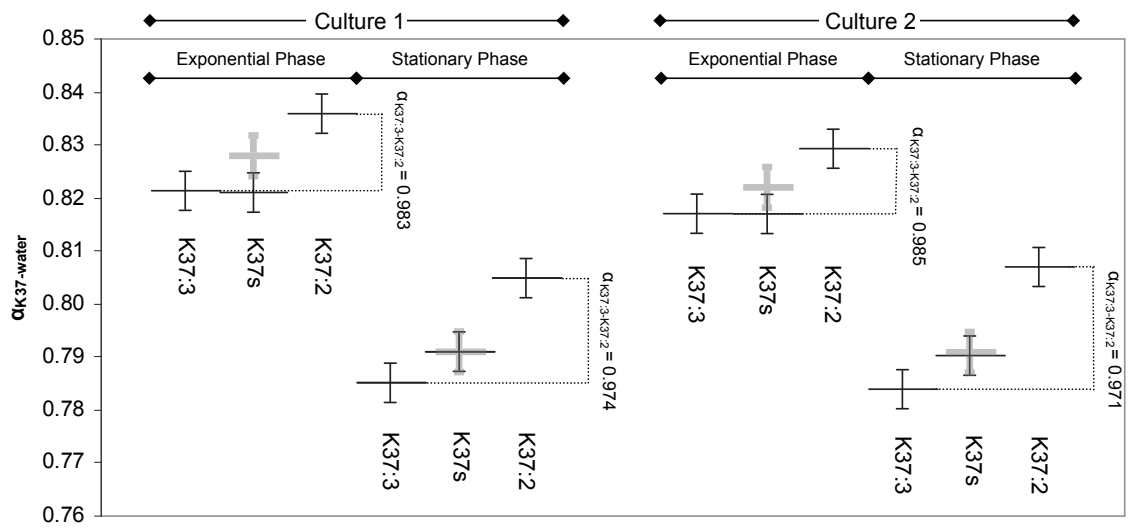

Fig. 3. Fractionation factors $(\alpha)$ relative to growth-water for the $15^{\circ} \mathrm{C}$ E. huxleyi growth-phase and unsaturation-specific fractionation experiments. Culture replicates 1 and 2 are shown on the left and right, respectively. Unseparated K37s samples for each culture replicate

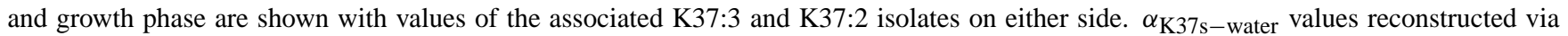
mass-balance for each pair of K37:2 and K37:3 measurements (Eq. 8), see Sect. 3.2) are shown by the shaded bars. Values of $\alpha_{\mathrm{K} 37: 3-\mathrm{K} 37: 2}$ are provided for each set of isolate measurements (see dashed lines).

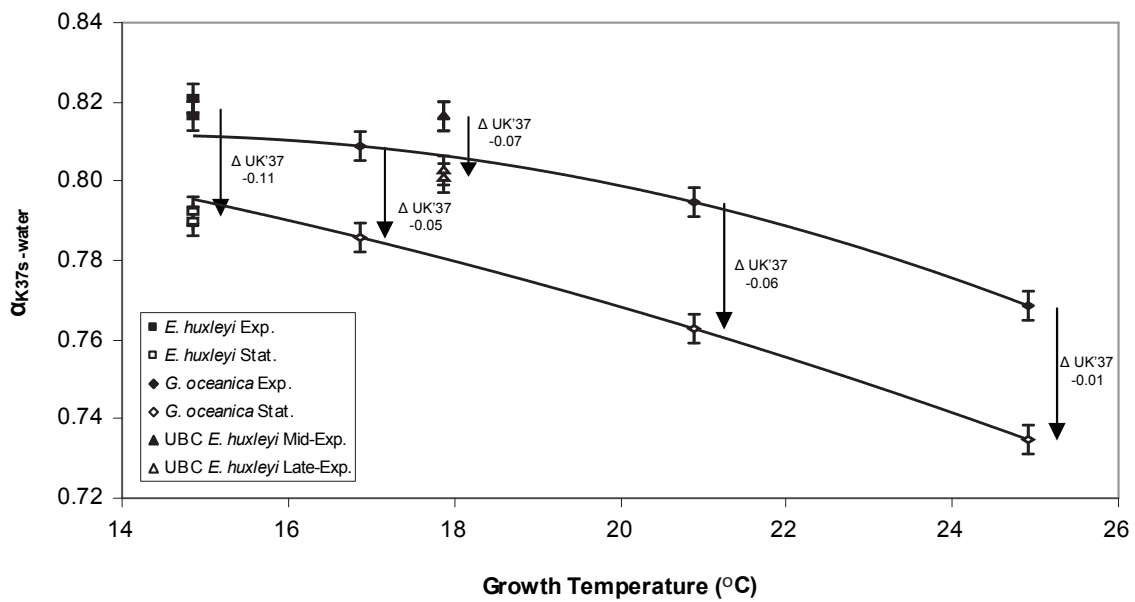

Fig. 4. Estimated fractionation factors relative to growth-water for the G. oceanica cultures. As a visual aide, lines are drawn to show the apparently smooth trend in the data for G. oceanica sampled in the exponential growth phase and at the onset of nutrient-depleted senescence. Values for the $U_{37}^{K^{\prime}}$ shift associated with transition between the exponential to stationary growth phases $\left(U_{37}^{K^{\prime}} \exp -U_{37}^{K^{\prime}}\right.$ stat) for each treatment are shown as an annotation. $\delta D_{\mathrm{K} 37 \mathrm{~s}}$ values for exponential and stationary growth phase samples of E. huxleyi from the primary experiment and the early- and late-exponential phase samples from the experiment run at UBC are plotted for comparison.

growth phase samples should plot below zero. The apparent deviation of only one compound may reflect an isotopic fractionation effect imparted by low recovery from the argentation chromatography procedure (Schwab and Sachs, 2009). Regardless of the cause, however, the observation justifies a revised analysis of the $\delta D_{\mathrm{K} 37: 3}$ results from both exponential-phase samples.

In our revised analysis, all $\delta D_{\mathrm{K} 37: 2}$ values are assumed to be robust, based on the consistent $\Delta \delta D$ values and uniformly high recovery ( $\sim 90 \%$, Fig. 5). Given this condition, the $\delta D_{\mathrm{K} 37: 3}$ value required to properly close the isotopic mass balance for the two experiments where K37:3 displayed conspicuously low recovery $(\sim 70 \%)$ can be calculated using an algebraic rearrangement of Eq. (8): $\delta D_{\mathrm{K} 37: 3, \text { calc }}=\frac{\delta D_{\mathrm{K} 37 \mathrm{~s}}-\delta D_{\mathrm{K} 37: 2} U_{37}^{K^{\prime}}}{1-U_{37}^{K^{\prime}}}$

The calculated $\delta D_{\mathrm{K} 37: 3}$ values average $-198.1 \pm 0.5 \%$ o

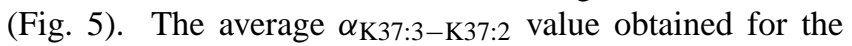
exponential growth phase samples when these "calculated" $\delta D_{\mathrm{K} 37: 3}$ values are used $(0.972 \pm 0.005)$ is statistically identical (two-sided $p=0.91$ ) to that assessed for stationary growth phase samples $(0.973 \pm 0.005)$. The weakness of this reconstruction lies in the assumption that the $\delta D_{\mathrm{K} 37: 2}$ values are correct. While the chromatographic technique employed was inherently different (normal-phase HPLC rather than argentation), Schwab and Sachs (2009) propose a threshold of $\sim 92 \%$ recovery of individual alkenones to ensure that no isotopic alteration occurred, a value slightly higher than 


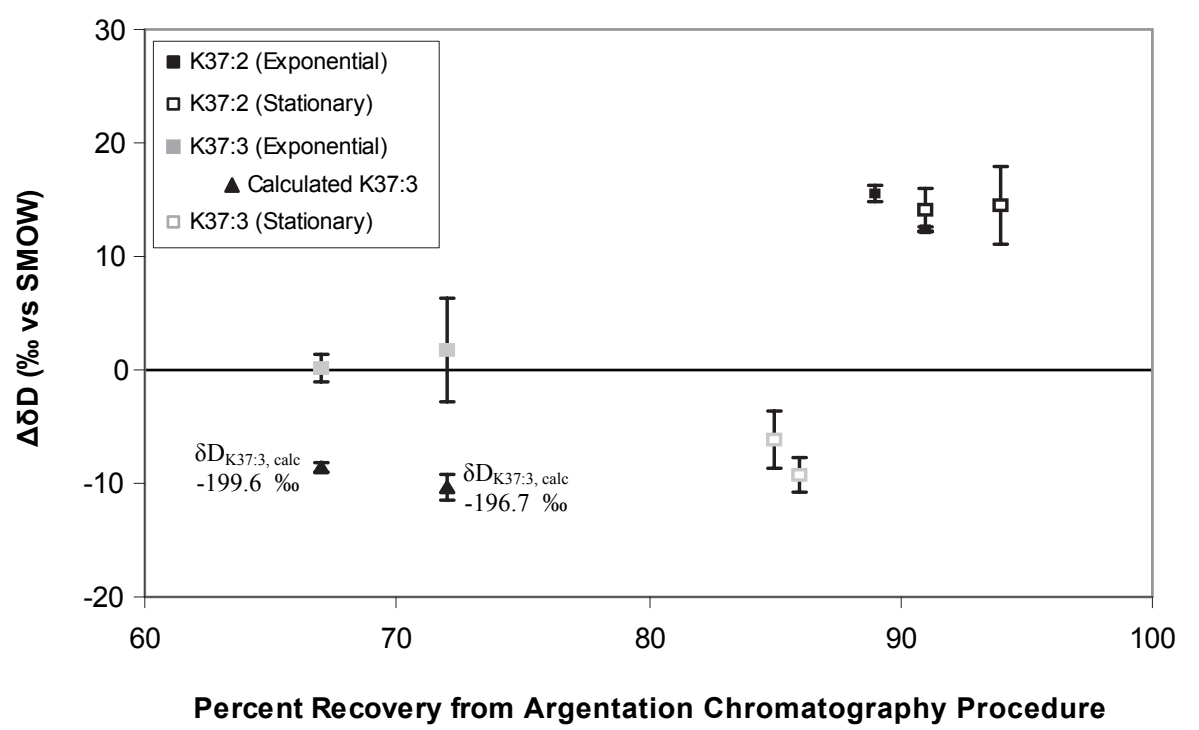

Fig. 5. Plot of differences between the $\delta D$ of the unsaturation-specific isolates and their associated integrated K37s values $\left(\Delta \delta D \equiv \delta D_{\mathrm{K} 37: \mathrm{n}}-\delta D_{\mathrm{K} 37 \mathrm{~s}}\right)$ from the $E$. huxleyi growth-phase experiments $\left(15^{\circ} \mathrm{C}\right.$ cultures) versus percent recovery from the argentation chromatographic procedure. Isotopic mass balance predictions (Eq. 9), see Sect. 4.1) for $\Delta \delta D$ values (absolute $\delta D$ values shown by annotation) for the exponential growth phase K37:3 isolates (triangles) are also shown.

those achieved in these experiments. Thus, while the issue of growth phase-dependence on the differential fractionation of K37:2 and K37:3 appears potentially resolved, the following discussion should be considered with these limitations in mind.

While the direction of the unsaturation-specific offset seen here agrees with the findings of D'Andrea et al. (2007), the magnitude of the fractionation effect does not. We find an average $\alpha_{\mathrm{K} 37: 3-\mathrm{K} 37: 2}$ value of $0.973 \pm 0.005$ while their result, 0.94 , is significantly lower (albeit without mass-balance constraints). It is possible that this difference is due to changes in $\alpha_{\mathrm{K} 37: 3-\mathrm{K} 37: 2}$ with growth conditions. However, D'Andrea et al. (2007) observed the same $\alpha$ value between K37:4 and K37:3 in two polar lacustrine sediments as between K37:3 and K37:2 in their E. huxleyi laboratory culture. This finding, coupled with the potential consistency of $\alpha_{\mathrm{K} 37: 3-\mathrm{K} 37: 2}$ across extremes in growth conditions documented here, suggests that $\alpha_{\mathrm{K} 37: \mathrm{n}-\mathrm{K} 37:(n-1)}$ may be a constant value independent of the species of alkenone producer or its physiological state.

Schwab and Sachs (2009) more recently reported values of $\alpha_{\mathrm{Kn}: 3-\mathrm{Kn}: 2}$ identical to ours $(\sim 0.97)$ for both $\mathrm{C}_{37}$ and $\mathrm{C}_{38}$ alkenones isolated from Chesapeake Bay sediment and suspended-particulate samples. The lack of $\mathrm{C}_{38}$ methyl components in the alkenone signature preserved in their sediment samples, however, is inconsistent with production by $E$. huxleyi (Volkman et al., 1980). The GC-illustrated molecular fingerprint documented in their publication is more indicative of alkenone-producing haptophytes such as Chrysotila lamellose (Rontani et al., 2004). This finding also suggests that an
$\alpha_{\mathrm{Kn}: 3-\mathrm{Kn}: 2}$ of $\sim 0.97$ may be applicable to various species of alkenone producers as well as across disparate growth conditions.

\subsection{Growth-phase dependence}

The net fractionation between total $\mathrm{C}_{37}$ alkenones and water differs between exponential- and stationary-phase cells (Fig. 3). This finding cannot solely reflect the $U_{37}^{K^{\prime}}$ change that occurs at the onset of senescence, as both the K37:2 and $\mathrm{K} 37: 3$ isolates exhibit an increase in hydrogen isotopic fractionation relative to water in the stationary growth phase samples (Fig. 3). The following exercise demonstrates that the quantitative effect of the change in relative compound abundance is minor. The average exponential-phase values of $\delta D_{\mathrm{K} 37: 2}(-174.9 \% o)$ and $\delta D_{\mathrm{K} 37: 3}(-198.1 \%$, "calculated" value), would correspond, given a $U_{37}^{K^{\prime}}$ value of 0.4 (observed here for exponential-phase samples) and Eq. (8), to a $\delta D_{\mathrm{K} 37 \mathrm{~s}}$ value of $-189 \%$ and an $\alpha_{\mathrm{K} 37 \text {-water }}$ of $\sim 0.818$. Were $U_{37}^{K^{\prime}}$ shifted to 0.3 (observed here for stationary-phase samples), these same compositions would yield a $\delta D_{\mathrm{K} 37 \mathrm{~s}}$ value of $-191 \%$ and an $\alpha_{\mathrm{K} 37-w a t e r}$ of 0.816 . This pair of hypothetical exponential- and stationary-phase samples would have an $\alpha_{\mathrm{K} 37-\text { water }}$ difference of 0.003 . This difference is within the uncertainty of our measurements and is much smaller than the 0.027 difference with growth phase that we observe for actual K37s samples. A real change in net biosynthetic fractionation has taken place, independent of the changing relative contributions of K37:3 and K37:2 to the "weighted average" $\delta D_{\mathrm{K} 37 \mathrm{~s}}$ measurements. 
A change in hydrogen isotopic composition with growth status may be expected, due to the changes in the routing of D-depleted $\mathrm{NADPH}^{+}$that occur (Schmidt et al., 2003). For example, Chikaraishi et al. (2004, 2009) showed isoprenoid synthetic products in a higher plant to be significantly more D-depleted than acetogenic lipids. In a simplified model where $\mathrm{NADPH}^{+}$formation remains constant, but this reducing power is shunted solely into acetogenic lipids (e.g. alkenones) and ceases being used to produce isoprenoid structural components (e.g. membrane lipids, phytol), mass balance would demand that the resulting acetogenic lipids be more depleted. Chemical restructurings such as this were seen by Zhang and Sachs (2009) when comparing the fatty acid and sterol content of nitrate-replete and nitrate-limited exponential-stage marine diatoms. Rather than a D-depletion of fatty acids, however, they observed approximately no change or a slight enrichment.

While this seems contradictory to our data, consider the hypothetical effect of a decrease or cessation of cell division on the intracellular water pool. In photoautotrophs, this pool is D-enriched due to $\mathrm{NADPH}^{+}$synthesis (Schmidt et al., 2003). If, as has been proposed for alkenone producers (Eltgroth et al., 2005), lipid synthesis serves as an important energy-management mechanism in the face of nutrient exhaustion, as opposed than the down-regulation of photosystem capacity, $\mathrm{NADPH}^{+}$production could still occur at a significant rate despite a halt to division. If the net incorporation of extracellular water to form new cytoplasm were stopped, one might then expect the intracellular water to become progressively more D-depleted as lipid synthesis continued.

Thus, one could imagine two potential processes, related to growth status, that would wield opposing effects on the $\delta D$ of acetogenic lipids - a decrease in the synthesis of D-depleted isoprenoid products, which, as discussed above, could drive the acetogenic lipids to more negative $\delta D$ values, and increased isolation of the intracellular water pool, which would drive them to more positive values. The fact, then, that Zhang and Sachs (2009) were observing A) different species of phytoplankton and B) the difference between two different exponential growth rates with different rate-limiters, as opposed to exponential and fully stationary growth as was studied here, means that their findings are not necessarily inconsistent with our own. Further research, particularly direct observations of the isotopic composition of intracellular water in photoautotrophs, is warranted.

Results from analysis of the G. oceanica samples show a similar offset between exponential- and stationary-phase samples (Fig. 4), indicating that the presence and approximate magnitude of the growth-phase effect on $\alpha_{\mathrm{K} 37 \mathrm{~s}-\text { water }}$ is not species-specific. The shift in estimated $\alpha_{\mathrm{K} 37 \mathrm{~s}-\text { water with }}$ growth phase for $G$. oceanica also appears to be independent of the decrease in $U_{37}^{K^{\prime}}$ which marks the onset of nutrientimposed stationary-phase growth at some temperatures. At $25^{\circ} \mathrm{C}$, there is only a minor decrease in $U_{37}^{K^{\prime}}$ associated with this transition in cell physiology (Fig. 4), but a large shift in
$\alpha_{\mathrm{K} 37 \mathrm{~s}-\text { water }}$ is still apparent. This observation further demonstrates there is true growth phase-dependence in $\alpha_{\mathrm{K} 37 \mathrm{~s}-\text { water }}$, independent of the changing proportion of K37:3 and $\mathrm{K} 37: 2$. Although not statistically verifiable given our limited data set, the apparent 'stress ' contours in the estimated $\alpha_{\mathrm{K} 37-\text { water }}$ versus growth-temperature data from the $G$. oceanica samples appear to extrapolate smoothly to the data from the $E$. huxleyi cultures. This observation suggests that both the growth-phase offset in isotopic fractionation and the absolute fractionation at each phase may be general to different species of alkenone-producing haptophytes (Fig. 4).

The apparent trend for stationary-phase G. oceanica measurements, which were obtained from cells collected at the onset of senescence, extrapolates to a position arguably above the stationary-phase data for E. huxleyi. The latter samples were harvested several days after the onset of nutrient-limited stationary-phase growth (Fig. 1). Additionally, the $G$. oceanica stationary-phase data interpolates to a point slightly below the late-exponential points from the UBC E. huxleyi cultures, which, based on previous measures of per-cell nitrogen content and assuming Redfield stoichiometry, had approximately one doubling worth of phosphate remaining in the culture medium at the time of harvest.

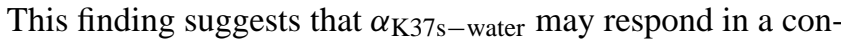
tinuous manner to the transition from one growth phase to another, and thus could provide a way to estimate the magnitude of stress. More work is needed in this area.

The apparent variation in $\alpha_{\mathrm{K} 37 \mathrm{~s}-\text { water }}$ with growth temperature also cannot be due to changes in $U_{37}^{K^{\prime}}$, as increased temperature leads to decreased relative abundance of $\mathrm{K} 37: 3$, the more deuterium-depleted of the component compounds, which would increase $\delta D_{\mathrm{K} 37 \mathrm{~s}}$. An increase in $\delta D_{\mathrm{K} 37 \mathrm{~s}}$ would, in turn, increase the value of $\alpha_{\mathrm{K} 37 \mathrm{~s}-\text { water, a trend opposite to }}$ the observation illustrated in Fig. 4. Our finding is in conflict with that of Schouten et al. (2006), who concluded that there

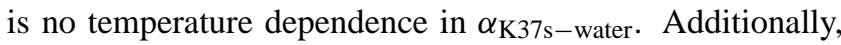

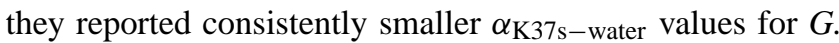
oceanica than for E. huxleyi when grown isothermally under a range of other environmental conditions. This result conflicts with the trend inferred from our yet-limited data set for these two organisms (Fig. 4). Zhang and Sachs (2009), however, did observe an increase in $\mathrm{D} / \mathrm{H}$ fractionation with temperature expressed in $\mathrm{C}_{16}$ fatty acids produced by two species of freshwater green algae, a result consistent with ours. A more thorough side-by-side study of G. oceanica and $E$. huxleyi is now warranted to test the veracity of these apparent trends with nutrient stress and temperature.

\subsection{Implications for paleoceanographic research}

Finding a value of $\alpha_{\mathrm{K} 37: 3-\mathrm{K} 37: 2}$ significantly less than unity raises a valid practical concern for any potential paleoceanographic application involving $\delta D_{\mathrm{K} 37 \mathrm{~s}}$ measurements. Our results, combined with those of others (D'Andrea et al., 2007; Schwab and Sachs, 2009), confirm that a significant isotopic 
offset between K37:3 and K37:2 does exist. For quantitative interpretations of paleoceanographic conditions, then, the impacts of changing $U_{37}^{K^{\prime}}$ must be taken into account. It is not currently practical to separate every sample and base interpretations on $\delta D$ analysis of pure, single compounds, both because it is time and labor intensive and because incomplete yields compromise results. Our data currently indicates that $\alpha_{\mathrm{K} 37: 3-\mathrm{K} 37: 2}$ may be a constant, in which case acceptable $\delta D_{K 37: n}$ values can be derived from $\delta D_{\mathrm{K} 37 \mathrm{~s}}$ and $U_{37}^{K^{\prime}}$ data. Although yield effects may compromise some of our data, we suggest that $\alpha_{\mathrm{K} 37: 3-\mathrm{K} 37: 2}$ has a constant value of $\sim 0.97$, consistent with the results of Schwab and Sachs (2009).

Variation in the hydrogen isotopic fractionation in alkenones relative to water, associated with nutrient stressinduced changes in growth phase, however, limits the use of $\delta D_{\mathrm{K} 37 \mathrm{~s}}$ as a paleoproxy for seawater isotopic composition. Surface sediment $\delta D_{\mathrm{K} 37 \mathrm{~s}}$ and overlying $\delta D_{\text {water }}$ data from the Scotian Margin (Englebrecht and Sachs, 2005) are consistent with an $\alpha_{\mathrm{K} 37-\text { water }}$, of $\sim 0.79$, the value our data (Fig. 4) predicts for stationary-phase cells grown at temperatures $<20^{\circ} \mathrm{C}$ (modern maSST $\approx 8^{\circ} \mathrm{C}$, World Ocean Atlas 2005). This field observation strengthens the argument that the alkenones preserved in sediments can reflect stressed organisms (Prahl et al., 2006). It is unknown to what degree, temporally or spatially, this condition applies to the geochemical record. Recent evidence suggests that the climatically significant statistical uncertainty in $U_{37}^{K^{\prime}}$ maSST reconstructions (i.e. $\pm 1.4^{\circ} \mathrm{C}$, Herbert, 2003) displays a significant degree of biogeographical coherence and, in some regions, may reflect the impact of significant non-thermal physiological effects (Prahl et al., 2009). $\delta D_{\mathrm{K} 37 \mathrm{~s}}$ measurements, then, could help to identify and quantify stress effects on $U_{37}^{K^{\prime}}$ paleotemperature estimates.

In open ocean settings, changes in $\delta D_{\text {water }}$ would have little impact on $\delta D_{\mathrm{K} 37 \mathrm{~s}}$ (see Sect. 1.1) relative to the variability that the effects of nutrient stress appear to impose on $\alpha_{\mathrm{K} 37 \mathrm{~s}-\text { water }}$ (Fig. 4). Thus, $\delta D_{\mathrm{K} 37 \mathrm{~s}}$ measurements could indicate whether changes in the nutrient regime, and the associated changes in $U_{37}^{K^{\prime}}$ imparted by variable nutrient stress, were a cause for time-variable discrepancies in different paleotemperature proxies, such as that described by Mix (2006) for $\mathrm{Mg} / \mathrm{Ca}$ and $U_{37}^{K^{\prime}}$ in the eastern tropical Pacific. Additionally, if $\alpha_{\mathrm{K} 37 \mathrm{~s}-\text { water }}$ indeed responds in a continuous rather than a stepwise manner to stress (Sect. 4.2), then $\delta D_{\mathrm{K} 37 \mathrm{~s}}$ could be used to correct, at least semi-quantitatively, for nutrient-stress biasing of $U_{37}^{K^{\prime}}$ temperature records by defining a continuum of unique $U_{37}^{K^{\prime}}$ vs. temperature relationships for contours of constant stress. To apply a calibration of this sort down-core, estimates of the isotopic composition of the surface water would be necessary in order to calculate $\alpha_{\mathrm{K} 37-\text { water }}$. $\delta D_{\text {water }}$ estimates could be derived, potentially, from $\delta^{18} \mathrm{O}$ measurements of planktonic-foraminiferal calcite and the initial $U_{37}^{K^{\prime}}$ temperature estimate. The effects of temperature proxy biasing of the scale we are discussing $\left(\sim 1^{\circ} \mathrm{C}\right)$ on values of $\delta D_{\text {water }}$ reconstructed from $\delta^{18} \mathrm{O}_{\text {calcite }}$ are small $(\sim 3 \%)$ relative to the changes we see between growth phases $(\sim 20 \%$ ). Thus, an approximation based on the initial SST estimate may be all that is required. This calibration "surface" ( $U_{37}^{K^{\prime}}$ vs. temperature vs. $\alpha_{\mathrm{K} 37-\text { water }}$ ), once adequately defined with considerably more data, could have the potential to collapse much of the scatter in environmental data into real variation in a third dimension.

The relationship between $\alpha_{\mathrm{K} 37 \mathrm{~s}-\text { water }}, U_{37}^{K^{\prime}}$, and temperature needs to be thoroughly evaluated by conducting more batch culture experiments, together with field testing in modern oceanographic settings, before the type of paleoproxy approach just discussed could be fruitfully realized. Knowledge gained from further study of stress-dependent behavior of $\alpha_{\mathrm{K} 37 \mathrm{~s}-\text { water }}$ in alkenone-producing haptophytes could lend valuable insight into ambiguous paleotemperature data sets. For this reason, it would seem a most worthwhile investment of future research effort.

\section{Conclusions}

Results from our batch culture experiments have shown:

1. K37:3 synthesized by E. huxleyi is fractionated, relative to the hydrogen isotopic composition of water in the growth medium, to a higher degree than K37:2. This difference appears constant across growth phases and, by comparison with the literature, between different species of alkenone-producers. We observe an $\alpha_{\mathrm{K} 37: 3-\mathrm{K} 37: 2}$ value of $\sim 0.97$. This value can be used, along with $U_{37}^{K^{\prime}}$ data and an assumption of isotopic mass balance, to estimate component $\delta D$ values. This approach would alleviate the need to perform timeconsuming, analytically difficult, and potentially yieldcompromised chromatographic separations on every sample.

2. Values of $\alpha_{\mathrm{K} 37 \mathrm{~s}-\text { water }}$ in both E. huxleyi and G. oceanica decrease when cells shift from the exponential to the nutrient-imposed stationary growth phase. This effect is not explained by growth phase-dependent changes in $U_{37}^{K^{\prime}}$ values altering the isotopic mass balance of the two component compounds. While biosynthetic mechanisms for this effect involving $\mathrm{NADPH}^{+}$utilization can be suggested, our incomplete understanding of alkenone biochemistry means that further investigation is clearly warranted.

These two conclusions suggest that $\delta D$ measurements of sedimentary alkenones may have utility as an indicator of stress impacts on the primary temperature signal encoded in $U_{37}^{K^{\prime}}$ values. Further development and future application of this measure as a stress index may help to improve the interpretation of $U_{37}^{K^{\prime}}$ temperature records and resolve discrepancies between proxies that are currently problematic for paleoceanographic/paleoclimatic research. 
Acknowledgements. We thank Alan Mix for allowing hands-on access to instrumentation in the COAS Stable Isotope Laboratory and extensive editorial assistance, Margaret Sparrow for assistance with analytical work, Alex Sessions for expert advice on making reliable compound specific $\delta D$ measurements, William Rugh for supplying water standards and providing invaluable technical expertise in making $\delta D_{\text {water }}$ measurements, Helmar Smits for synthesizing our K36:0 recovery standard, and the National Science Foundation for all financial support of this research effort (OCE-0326573 and -0601910). We also thank two anonymous reviewers for invaluable critical assessments and suggestions.

Edited by: J. Middelburg

\section{References}

Benway, H. M. and Mix, A. C.: Oxygen isotopes, upper-ocean salinity, and precipitation sources in the eastern tropical Pacific, Earth Planet. Sci. Lett., 224, 493-507, 2004.

Bidigare, R. R., Fluegge, A., Freeman, K. H., Hanson, K. L., Hayes, J. M., Hollander, D., Jasper, J. P., King, L. L., Laws, E. A., Milder, J., Millero, F. J., Pancost, R., Popp, B. N., Steinberg, P. A., and Wakeham, S. G.: Consistent fractionation of ${ }^{13} \mathrm{C}$ in nature and in the laboratory: Growth-rate effects in some haptophyte algae, Global Biogeochem. Cy., 11, 279-292, 1997.

Brassell, S. C.: Applications of biomarkers for delineating marine paleoclimatic fluctuations during the Pleistocene, in: Organic Geochemistry: Principles and Applications, edited by: Engel, M. H. and Macko, S. A., Plenum, 699-738, 1993.

Chikaraishi, Y., Suzuki, Y., and Naraoka, H.: Hydrogen isotopic fractionations during desaturation and elongation associated with polyunsaturated fatty acid biosynthesis in marine macroalgae, Phytochemistry, 65, 2293-2300, 2004.

Chikaraishi, Y., Tanaka, R., Tanaka, A., and Ohkouchi, N.: Fractionation of hydrogen isotopes during phytol biosynthesis, Org. Geochem., 40, 569-573, 2009.

Christie, W. W.: Lipid Analysis: Isolation, Separation, Identification and Structural Analysis of Lipids, 3rd edition, The Oily Press, 2003.

Conte, M. H., Eglinton, G., Madureira, L. A. S., Rabouille, C., Labeyrie, L., and Mudge, S.: Origin and fate of organic biomarker compounds in the water column and sediments of the eastern North Atlantic, Philos. T. Roy. Soc. B, 348, 169-178, 1995.

Craig, H.: Isotopic Variations in Meteoric Waters, Science, 133, 1702-1703, 1961.

Craig, H. and Gordon, L. I.: Isotopic oceanography - deuterium and oxygen 18 variations in the ocean and the marine atmosphere, in: Proceedings of the Symposium on Marine Geochemistry, 3, University of Rhode Island Occasional Publication, 277-374, 1965.

D’Andrea, W. J., Liu, Z., Alexandre, M. D., Wattley, S., Herbert, T. D., and Huang, Y.: An efficient method for isolating individual long-chain alkenones for compound-specific hydrogen isotope analysis, Anal. Chem., 79, 3430-3435, 2007.

Dansgaard, W.: Stable isotopes in precipitation, Tellus, 16, 436467, 1964.

de Vernal, A., Hillaire-Marcel, C., Turon, J. L., and Matthiessen, J.: Reconstruction of sea-surface temperature, salinity, and seaice cover in the northern North Atlantic during the last glacial maximum based on dinocyst assemblages, Can. J. Earth Sci., 37, 725-750, 2000.

Eltgroth, M. L., Watwood, R. L., and Wolfe, G. V.: Production and cellular localization of neutral long-chain lipids in the haptophyte algae Isochrysis galbana and Emiliania huxleyi, J. Phycol., 41, 1000-1009, 2005.

Englebrecht, A. C. and Sachs, J. P.: Determination of sediment provenance at drift sites using hydrogen isotopes and unsaturation ratios in alkenones, Geochim. Cosmochim. Ac., 69, 42534265, 2005.

Friedman, I., Redfield, A. C., Schoen, B., and Harris, J.: The variation of the deuterium content of natural waters in the hydrologic cycle, Rev. Geophys., 2, 177-224, 1964.

Herbert, T. D.: Alkenone Paleotemperature Determinations, in: Treatise on Geochemistry, Volume 6, edited by: Turekian, K. K. and Holland, H. D., Elsevier, Oxford UK, 391-432, 2003.

Jasper, J. P., Hayes, J. M., Mix, A. C., and Prahl, F. G.: Photosynthetic fractionation of ${ }^{13} \mathrm{C}$ and concentrations of dissolved $\mathrm{CO}_{2}$ in the central equatorial Pacific during the last 225,000 years, Paleoceanography, 9, 781-798, 1994.

Kreuzer-Martin, H. W., Ehleringer, J. R., and Hegg, E. L.: Oxygen isotopes indicate most intracellular water in log-phase Escherichia coli is derived from metabolism, P. Natl. Acad. Sci. USA, 102, 17337-17341, 2005.

Laws, E. A., Popp, B. N., Bidigare, R. R., Kennicutt, M. C., and Macko, S. A.: Dependence of phytoplankton carbon isotopic composition on growth rate and $\left[\mathrm{CO}_{2}\right]_{a q}$ : Theoretical considerations and experimental results, Geochim. Cosmochim. Ac., 59, 1131-1138, 1995.

Maldonado, M. T., Allen, A. E., Chong, J. S., Lin, K., Leus, D., Karpenko, N., and Harris, S. L.: Copper-dependent iron transport in coastal and oceanic diatoms, Limnol. Oceanogr., 51, 17291743, 2006.

Mercer, J. L., Zhao, M., and Colman, S. M.: Seasonal variations of alkenones and UK37 in the Chesapeake Bay water column, Estuarine, Coastal and Shelf Science, 63, 675-682, 2005.

Mix, A. C.: Running hot and cold in the eastern equatorial Pacific, Quaternary Sci. Rev., 25, 1147-1149, 2006.

Müller, P. J., Kirst, G., Ruhland, G., von Storch, I., and RosellMelé, A.: Calibration of the alkenone paleotemperature index UK' 37 based on core-tops from the eastern South Atlantic and the global ocean $\left(60^{\circ} \mathrm{N}-60^{\circ} \mathrm{S}\right)$, Geochim. Cosmochim. Ac., 62, 1757-1772, 1998.

Nikolova-Damyanova, B.: Silver ion chromatography and lipids, in: Advances in Lipid Methodology, Volume One, edited by: Christie, W. W., The Oily Press, 181-237, 1992.

Pahnke, K., Sachs, J. P., Keigwin, L., Timmermann, A., and Xie, S.: Eastern tropical Pacific hydrologic changes during the past 27,000 years from D/H ratios in alkenones, Paleoceanography, 22, PA4214, doi:10.1029/2007PA001468, 2007.

Prahl, F. G., de Lange, G. J., Lyle, M., and Sparrow, M. A.: Postdepositional stability of long-chain alkenones under contrasting redox conditions, Nature, 341, 434-437, 1989.

Prahl, F. G., Mix, A. C., and Sparrow, M. A.: Alkenone paleothermometry: Biological lessons from marine sediment records off western South America, Geochim. Cosmochim. Ac., 70, 101117, 2006.

Prahl, F. G., Rontani, J.-F., Zabeti, N., Walinsky, S. E., and Sparrow, M. A.: Systematic patterns in UK'37 - temperature resid- 
uals for surface sediments from high latitude and other oceanographic settings, Geochim. Cosmochim. Ac., in press, 2009.

Prahl, F. G. and Wakeham, S. G.: Calibration of unsaturation patterns in long-chain ketone compositions for palaeotemperature assessment, Nature, 330, 367-369, 1987.

Prahl, F. G., Wolfe, G. V., and Sparrow, M. A.: Physiological impacts on alkenone paleothermometry, Paleoceanography, 18, 1025, doi:10.1029/2002PA000803, 2003.

Rohling, E. J.: Progress in paleosalinity: Overview and presentation of a new approach, Paleoceanography, 22, 3215, doi:10.1029/2007PA001437, 2007.

Rontani, J.-F., Beker, B., and Volkman, J. K.: Long-chain alkenone and related compounds in the benthic haptophyte Chrysotila lamellosa Anand HAP 17, Phytochemistry, 65, 117-126, 2004.

Rontani, J.-F., Prahl, F. G., and Volkman, J. K.: Re-examination of the double bond positions in alkenone and derivatives: Biosynthetic implications, J. Phycol, 42, 800-813, 2006.

Schmidt, H.-L., Werner, R. A., and Eisenreich, W.: Systematics of ${ }^{2} \mathrm{H}$ patterns in natural compounds and its importance for the elucidation of biosynthetic pathways, Phytochem. Rev., 2, 6185, 2003.

Schouten, S., Ossebaar, J., Schreiber, K., Kienhuis, M. V. M., Langer, G., Benthien, A., and Bijma, J.: The effect of temperature, salinity and growth rate on the stable hydrogen isotopic composition of long chain alkenones produced by Emiliania huxleyi and Gephyrocapsa oceanica, Biogeosciences, 3, 113-119, 2006, http://www.biogeosciences.net/3/113/2006/.

Schwab, V. F. and Sachs, J. P.: The measurement of D/H ratio in alkenones and their isotopic heterogeneity, Org. Geochem., 40, 111-118, 2009.
Sessions, A. L., Burgoyne, T. W., Schimmelmann, A., and Hayes, J. M.: Fractionation of hydrogen isotopes in lipid biosynthesis, Org. Geochem., 30, 1193-1200, 1999.

Smittenberg, R. H. and Sachs, J. P.: Purification of dinosterol for hydrogen isotopic analysis using high-performance liquid chromatography-mass spectrometry, J.Chromatogr. A, 1169, 7076, 2007.

van der Meer, M. T. J., Sangiorgi, F., Baas, M., Brinkhuis, H., Sinninghe Damsté, J. S., and Schouten, S.: Molecular isotopic and dinoflagellate evidence for Late Holocene freshening of the Black Sea, Earth Planet. Sci. Lett., 267, 426-434, 2008.

Volkman, J. K., Eglinton, G., Corner, E. D. S., and Sargent, J. R.: Novel unsaturated straight-chain C37-C39 methyl and ethyl ketones in marine sediments and a coccolithophore Emiliania huxleyi, in: Advances in Organic Geochemistry, 1979: Proceedings of the Ninth International Meeting on Organic Geochemistry, edited by: Douglas, A. G. and Maxwell, J. R., Pergamon Press, 219-227, 1980.

West, A. G., Patrickson, S. J., and Ehleringer, J. R.: Water extraction times for plant and soil materials used in stable isotope analysis, Rapid Commun. Mass Sp., 20, 1317-1321, 2006.

Yakir, D. and DeNiro, M. J.: Oxygen and hydrogen isotope fractionation during cellulose metabolism in Lemna gibba L., Plant Physiol., 93, 325-332, 1990.

Zhang, Z., Sachs, J. P., and Marchetti, A.: Hydrogen isotope fractionation in freshwater and marine algae: II. Temperature and nitrogen limited growth rate effects, Org. Geochem., 40, 428-439, 2009. 